\title{
Thermosensitive Poly(N-vinylcaprolactam) Injectable Hydrogels for Cartilage Tissue Engineering
}

\author{
Renata L. Sala, MSc, ${ }^{1,2}$ Mi Y. Kwon, BS, Minwook Kim, PhD, ${ }^{3,4}$ Sarah E. Gullbrand, PhD, 3,4 \\ Elizabeth A. Henning, PhD, ${ }^{3,4}$ Robert L. Mauck, $\mathrm{PhD}^{2-4}$ Emerson R. Camargo, PhD, and Jason A. Burdick, $\mathrm{PhD}^{2}$
}

Injectable hydrogels have gained prominence in the field of tissue engineering for minimally invasive delivery of cells for tissue repair and in the filling of irregular defects. However, many injectable hydrogels exhibit long gelation times or are not stable for long periods after injection. To address these concerns, we used thermosensitive poly $(\mathrm{N}-$ vinylcaprolactam) (PNVCL) hydrogels due to their cytocompatibility and fast response to temperature stimuli. Changes in the PNVCL molecular weight and concentration enabled the development of hydrogels with tunable mechanical properties and fast gelation times $(<60 \mathrm{~s}$ when the temperature was raised from room temperature to physiologic temperature). Chondrocytes (CHs) and mesenchymal stem cells were encapsulated in PNVCL hydrogels and exhibited high viability ( $\sim 90 \%$ ), as monitored by Live/Dead staining and Alamar Blue assays. Three-dimensional constructs of CH-laden PNVCL hydrogels supported cartilage-specific extracellular matrix production both in vitro and after subcutaneous injection in nude rats for up to 8 weeks. Moreover, biochemical analyses of constructs demonstrated a time-dependent increase in glycosaminoglycans (GAGs) and collagen, which were significantly augmented in the implants cultured in vivo. Histological analyses also demonstrated regular distribution of synthesized cartilage components, including abundant GAGs and type II collagen. The findings from this study demonstrate thermosensitive PNVCL as a candidate injectable biomaterial to deliver cells for cartilage tissue engineering.

Keywords: cartilage, hydrogels, injectable

\section{Introduction}

$\mathbf{C}$ ARTILAGE TISSUE ENGINEERING is needed due to the limited ability of native cartilage to self-repair and regenerate after damage. This necessitates new technologies and approaches to repair damage to articular cartilage, typically caused by traumatic injury and osteoarthritis that is increasingly common, especially in an aging population. ${ }^{1-3}$ Typical clinical treatments for articular cartilage repair involve microfracture, autologous chondrocyte $(\mathrm{CH})$ implantation, osteochondral allograft transplantation, and scaffold base techniques. ${ }^{4}$ Although these therapies have reduced pain and delayed cartilage degeneration, they have limitations such as the need for complicated surgical procedures, risk of infections, poor integration with the surrounding tissue, and formation of fibrocartilage that has inferior mechanical and chemical properties compared to hyaline cartilage. ${ }^{1,2,4-6}$
To overcome these limitations, cell-based constructs have emerged that integrate $\mathrm{CHs}$, biochemical signals, and three-dimensional (3D) scaffolds to create an engineered cartilage tissue. ${ }^{7}$ These constructs are usually composed of synthetic or natural hydrogels that can encapsulate cells, be modified to have specific mechanical properties, exhibit controlled degradation, and possess a permeable matrix for the diffusion of soluble factors, all of which can enable or promote neocartilage formation. ${ }^{7-11}$ However, preformed scaffolds demand surgical procedures for implantation, increasing the risk of infection and potentially poor integration to the defect site. ${ }^{5,12}$ Alternatively, injectable hydrogels overcome many of these concerns, since they are formed during or after the injection process. ${ }^{13}$ In this way, they can be implanted in a minimally invasive manner, provide better defect margin adaptation, and can incorporate cells, therapeutic drugs, and growth factors, which will

\footnotetext{
${ }^{1}$ Interdisciplinary Laboratory of Electrochemistry and Ceramics, Department of Chemistry, Federal University of São Carlos, São Carlos, Brazil.

${ }^{2}$ Department of Bioengineering, University of Pennsylvania, Philadelphia, Pennsylvania.

${ }^{3}$ McKay Orthopaedic Research Laboratory, Department of Orthopaedic Surgery, Perelman School of Medicine, University of Pennsylvania, Philadelphia, Pennsylvania.

${ }^{4}$ Translational Musculoskeletal Research Center, CMC VA Medical Center, Philadelphia, Pennsylvania.

*This article is part of a special focus issue on Strategic Directions in Musculoskeletal Tissue Engineering. Additional articles can be found in Tissue Engineering Part A, volume 23, numbers 15-16 and Tissue Engineering Part B, number 4.
} 
stimulate the formation of extracellular matrix (ECM) and the repair of cartilage tissue. ${ }^{2,5,12}$

Injectable hydrogels are formed due to the in situ transition from a liquid phase to a gel state through the formation of a 3D polymeric network as a result of chemical bonds or physical interactions between polymer chains. ${ }^{14}$ Chemically cross-linked hydrogels can be formed by reactions such as radical polymerizations, ${ }^{9}$ click chemistry, ${ }^{15}$ Michael-type addition reactions, ${ }^{16}$ and dynamic covalent chemistry, ${ }^{17}$ forming in most cases irreversible cross-links. ${ }^{13}$ Alternatively, hydrogels can be formed by physical interactions as result of external stimuli, such as heat and $\mathrm{pH},{ }^{18,19}$ or intermolecular assemblies, such as guest-host bonds, ${ }^{20,21}$ resulting in networks with reversible bonds. ${ }^{13}$ Particularly, thermosensitive hydrogels undergo a sol-gel transition, based on hydration-dehydration processes according to temperature changes. ${ }^{22,23}$ Such hydrogels present a lower critical solution temperature (LCST), which is the temperature where the sol-gel transition occurs. ${ }^{24}$ Specifically, the thermosensitive polymer is dispersed in an aqueous solution, where the polymer chains swell in a random coil conformation due to hydrophilic interactions with water molecules; however, when the system is heated past the LCST, the polymer chains aggregate and collapse due to predominant hydrophobic interactions between polymer chains. ${ }^{18}$

Some thermosensitive polymers, for instance, poly $(\mathrm{N}$ isopropylacrylamide) (PNIPAm) and poly(N-vinylcaprolactam) (PNVCL), have LCST values similar to physiological temperatures. Therefore, these materials can transition from a liquid to a gel and form an in-situ hydrogel when injected into the body, without additional chemical reactions, cross-linkers, or environmental treatments. ${ }^{13,24}$ Although both of these polymers have similar thermoresponsive behaviors, PNVCL does not produce toxic compounds when degraded and has demonstrated improved cell viability compared to PNIPAm..$^{22,23,25,26}$ PNVCL assemblies degrade through the dissociation of the polymers over time, which leads to material erosion. With these characteristics and general consideration of biocompatibility, PNVCL is a promising biomaterial for biomedical applications and has gained attention, especially for therapeutic delivery and entrapment of enzymes. ${ }^{27-29}$ However, there has been little work toward the use of PNVCL in tissue engineering, especially when dealing with the investigation of cell-material interactions and tissue formation in vitro and in vivo. ${ }^{30-32}$

In the present work, we report the development and application of an injectable PNVCL hydrogel for cartilage tissue engineering. PNVCL hydrogels were synthesized with two different polymer molecular weights (MWs) and with sol-gel transition at physiological temperature. The mechanical properties against temperature and time were investigated by rheological analysis and tailored through PNVCL MW and concentration. Furthermore, the cytocompatibility and formation of tissue both in vitro and in vivo were assessed with encapsulated bovine $\mathrm{CHs}$ and human mesenchymal stem cells (MSCs). This work is an important step toward the development of noninvasive material-based approaches for cartilage repair.

\section{Materials and Methods}

\section{Synthesis of PNVCL}

PNVCL was synthesized through modification of a procedure by Medeiros et al. ${ }^{33}$ PNVCL with lower (PNVCL-L,
$\mathrm{M}_{\mathrm{n}}=12.9 \mathrm{kDa}$, polydispersity index $[\mathrm{PDI}]=5$ ) or higher (PNVCL-H, $\mathrm{M}_{\mathrm{n}}=142.7 \mathrm{kDa}, \mathrm{PDI}=5$ ) MWs were synthesized by initially adding $15 \%$ or $5 \% \mathrm{w} / \mathrm{w}$ of $\mathrm{N}$-vinylcaprolactam monomer ( $\geq 98 \%$; Sigma-Aldrich) in the solvents dimethyl sulfoxide (DMSO, anhydrous, $\geq 99.9 \%$; Sigma-Aldrich) and distilled water, respectively. Then, $2 \% \mathrm{w} / \mathrm{w}$ of $2,2^{\prime}$-azobis(2methylpropionitrile) (AIBN, 98\%; Sigma-Aldrich), previously recrystallized in methanol, was added to the reaction system at $70^{\circ} \mathrm{C}$ under nitrogen atmosphere. Within $4 \mathrm{~h}$ the polymerization was already completed and the PNVCL was purified by dialysis (MW cutoff $3.5 \mathrm{kDa}$ ) against deionized water during 4 days with repeated changes of water. PNVCL was then lyophilized and stored at $4^{\circ} \mathrm{C}$ before use.

\section{Characterization of PNVCL}

PNVCL-L and PNVCL-H molecular structures were analyzed by ${ }^{1} \mathrm{H}$ NMR (DMX $360 \mathrm{MHz}$; Bruker, Billerica, MA). Chemical shifts $(\delta)$ are reported in ppm relative to $\mathrm{D}_{2} \mathrm{O}(\delta=4.81 \mathrm{ppm})$. Four hydrogen resonances were found in PNVCL-L and PNVCL-H spectra. They are assigned to: methylene groups from caprolactam ring and backbone $(6 \mathrm{H}$, $2 \mathrm{H}, \delta=1.8 \mathrm{ppm})$, close to $\mathrm{C}=\mathrm{O}(2 \mathrm{H}, \delta=2.4 \mathrm{ppm})$, and close to $\mathrm{N}(2 \mathrm{H}, \delta=3.4 \mathrm{ppm})$ and $-\mathrm{NCH}-(1 \mathrm{H}, \delta=4.4 \mathrm{ppm})$. Ultraviolet (UV)-vis spectroscopy (MultiSpec-1501 UV-vis Spectrophotometer Shimadzu) coupled with a Peltier control device (TCC-Controller Shimadzu 240) was applied to determine the LCST values of both polymers. For this, the transmittance of a diluted aqueous polymer solution $(1 \% \mathrm{w} / \mathrm{v})$ was measured at a wavelength of $500 \mathrm{~nm}$ from $25^{\circ} \mathrm{C}$ to $35^{\circ} \mathrm{C}$. The temperature was allowed to stabilize before the measurement of the transmittance.

Rheological analysis was performed on an AR2000 rheometer (TA Instruments), coupled with a Peltier control device $(20 \mathrm{~mm}$ diameter cone and plate geometry, $59 \mathrm{~min}$ $42 \mathrm{~s}$ cone angle, gap of $27 \mu \mathrm{m})$. Storage $\left(\mathrm{G}^{\prime}\right)$ and loss $\left(\mathrm{G}^{\prime \prime}\right)$ moduli from PNVCL-L (10-30\% w/v in phosphate-buffered saline [PBS]) and PNVCL-H (5-20\% w/v in PBS) were evaluated at the temperature range of $25-37^{\circ} \mathrm{C}$, at $3^{\circ} \mathrm{C} / \mathrm{min}$, $0.5 \%$ strain, and $1 \mathrm{~Hz}$. The time to reach elevated mechanical properties at $37^{\circ} \mathrm{C}$ was investigated by time sweep $(300 \mathrm{~s}, 0.5 \%$ strain, $1 \mathrm{~Hz})$ of intermediate concentrations of polymers-PNVCL-L (20\% w/v) and PNVCL-H (10\% w/v).

\section{Cell isolation and expansion}

Bovine $\mathrm{CHs}$ were isolated from juvenile bovine joints (Research 87, Boylston, MA), and maintained and expanded through passage 1 in basal medium, which consists of highglucose Dulbecco's modified Eagle's medium (DMEM) supplemented with $10 \% \mathrm{v} / \mathrm{v}$ fetal bovine serum (FBS; Gibco-Invitrogen) and $1 \% \mathrm{v} / \mathrm{v}$ penicillin/streptomycin/fungizone (PSF; Gibco-Invitrogen). ${ }^{3,34}$ Human MSCs (Lonza) were maintained and expanded to passage 3 in growth media, which consists of minimum essential medium $\alpha$ supplemented with $16.7 \%$ w/v FBS (Gibco-Invitrogen) and 1\% penicillin/streptomycin (Gibco-Invitrogen).

\section{Cytotoxicity studies}

Cytotoxicity of PNVCL-L and PNVCL-H was assessed by an Alamar Blue (AB) assay to measure viability of $\mathrm{CHs}$ and MSCs. Initially, CHs and MSCs were suspended in 
basal and growth media, respectively, seeded in a 96-well plate at a density of $1 \times 10^{4}$ cells per well, and incubated at $37^{\circ} \mathrm{C}, 5 \% \mathrm{CO}_{2}$ for $24 \mathrm{~h}$. Then, the media (total volume of $100 \mu \mathrm{L})$ was replaced with the appropriate polymers resuspended in media at a series of concentrations from 0.001 to $1 \mathrm{mg} / \mathrm{mL}$ and incubated for $24 \mathrm{~h}$. Subsequently, media containing polymer was removed, and the cells were washed with PBS thrice at room temperature before being replaced by $100 \mu \mathrm{L}$ per well of AB solution $\left(10 \% \mathrm{w} / \mathrm{w}\right.$ of alamarBlue ${ }^{\circledR}$ in serum-free basal medium). After incubation at $37^{\circ} \mathrm{C}$ for $4 \mathrm{~h}$, the absorbance of each sample $(n=4)$ was measured in a microplate reader (excitation wavelength $=540 \mathrm{~nm}$, emission wavelength $=610 \mathrm{~nm})$. Cell viability $(\%)$ was calculated according to the absorbance values measured and normalized to the absorbance of control wells, in which seeded cells were incubated in the presence of media alone.

\section{Three-dimensional cell viability and in vitro studies}

$\mathrm{CHs}$ and MSCs were resuspended at a concentration of 20 million cells/mL in PNVCL-L (20\% w/v) and PNVCL-H $(10 \% \mathrm{w} / \mathrm{v})$. Then, $50 \mu \mathrm{L}$ of these suspensions were injected using hypodermic needles of various gauges (18G, 21G, 27G) into custom polydimethylsiloxane circular molds adhered to $12 \mathrm{~mm}$ plasma-treated glass coverslips and placed inside a $24-$ well plate. They were then incubated at $37^{\circ} \mathrm{C}$ for gelation, and $2 \mathrm{~mL}$ of basal or growth media was added. On the day of injection (day 0) and after 3 days (day 3), cell viability in the encapsulated materials was assessed by a Live/Dead Assay Kit (Molecular Probes) with the use of confocal microscopy (TCS SP5; Leica) to image throughout the construct volume. Live cells, stained green with calcein-AM, and dead cells, stained red with ethidium homodimer, were quantified. In vitro studies to investigate neocartilage formation were performed with CH-laden PNVCL-L and PNVCL-H cultured in the presence of $2 \mathrm{~mL}$ of chondrogenic medium (high-glucose DMEM, 1\% v/v Corning ${ }^{\circledR}$ ITS Premix Universal Culture Supplement, $50 \mathrm{mg} / \mathrm{mL}$ L-proline, $0.1 \mathrm{mM}$ dexamethasone, $0.9 \mathrm{mM}$ sodium pyruvate, $50 \mathrm{mg} / \mathrm{mL}$ ascorbate, and $1 \% \mathrm{v} / \mathrm{v}$ of PSF), ${ }^{9}$ which was replaced thrice a week over 4 and 8 weeks.

\section{Subcutaneous injection in nude rats}

$\mathrm{CH}-$ laden and acellular hydrogels of PNVCL-L (20\% w/v) and PNVCL-H $(10 \% \mathrm{w} / \mathrm{v})$ at 20 million cells $/ \mathrm{mL}$ were prepared as previously described and injected with a hypodermic needle $(21 \mathrm{G})$ subcutaneously in male athymic nude rats (aged 9-10 weeks), under inhalational anesthesia (2\% vaporized isoflurane in the supply gas [oxygen]), and using standard aseptic techniques. A total of 10 subcutaneous injections per timepoint, $200 \mu \mathrm{L}$ per injection, were administered for each CH-laden hydrogel $(n=8)$, and 2 injections of acellular samples $(n=2)$ were used as controls. Samples were explanted at 4 and 8 weeks. This in vivo study was approved by the Institutional Animal Care and Use Committee at the University of Pennsylvania and the Philadelphia VA Medical Center.

\section{Biochemical and histological analyses}

At 4 and 8 weeks, the in vitro and in vivo $\mathrm{CH}$-laden hydrogels $(n=4)$ were weighed, lyophilized, and then digested in $0.75 \mathrm{mg} / \mathrm{mL}$ of papain (Sigma) at $60^{\circ} \mathrm{C}$ for $48 \mathrm{~h}$.
The glycosaminoglycan (GAG) content in these samples was determined using the dimethylmethylene blue (DMMB) assay (Sigma-Aldrich), using a standard curve of bovine chondroitin 4-sulfate. 9,35 Collagen content was also determined using the orthohydroxyproline (OHP) assay, using a trans-4-hydroxy-L-proline (Sigma-Aldrich) standard curve, and quantified according to the known ratio 1:7.14 of OHP:collagen. ${ }^{34,36}$ Acellular constructs were also evaluated in both assays as control groups, showing no interference in the data obtained.

$\mathrm{CH}$-laden and acellular implants removed from the rats after 4 and 8 weeks were processed for histology in paraffin $(n=3)$. Sections of $7 \mu \mathrm{m}$ of thickness were stained with Alcian blue ( $\mathrm{pH}$ 2.5) for proteoglycans and immunostained for collagen type I and II (Col I and Col II, respectively). Sections were imaged by bright-field microscopy (Olympus BX51), and quantification of the mean staining intensity of implants was measured using ImageJ, by converting the images to 8-bit grayscale.

\section{Statistical analysis}

Statistical analysis was performed using Excel software with Daniel's XL Toolbox add-in. Significance between groups ( $n=4$ per group) was determined by one-way analysis of variance (ANOVA) with Tukey's post hoc test $(p<0.05)$, and error bars represent standard error of the mean.

\section{Results and Discussion}

\section{Synthesis and characterization of PNVCL}

PNVCL, a prominent injectable and biocompatible material that undergoes a transition phase at physiological temperature, is still poorly explored as a potential hydrogel material for tissue engineering. To understand the potential of PNVCL as an injectable biomaterial for cartilage tissue engineering, two polymers (PNVCL-L and PNVCL-H) with distinct MWs (PNVCL-L, $\mathrm{M}_{\mathrm{n}, \mathrm{GPC}}=12.9 \mathrm{kDa}$; PNVCL-H, $M_{n, G P C}=142.7 \mathrm{kDa}$ ) were synthesized by tuning synthesis parameters (Fig. 1a). PNVCL-L was obtained in a homogenous system of solvent (DMSO), monomer, and radical initiator, whereas PNVCL-H was prepared in a heterogeneous system with water and the formation of a precipitated polymer during the reaction at $70^{\circ} \mathrm{C}$ (above its transition phase temperature). In both systems, a pure phase of linear PNVCL was obtained after $4 \mathrm{~h}$ of reaction. However, the precipitation polymerization led to a higher MW, which is usually attributed to a higher ratio of the propagation to termination rate compared to a homogenous system. ${ }^{37}$ Lozinsky et $a l .{ }^{38}$ also observed an increase in the MW during the synthesis of PNVCL using a mixture of water/DMSO as the solvent compared to synthesis in DMSO alone.

The MW of PNVCL can also influence LCST values during the sol-gel transition. The reduction of the transmittance with temperature of a PNVCL aqueous suspension indicates the transition of the thermosensitive polymer from sol (transparent) to gel (opaque), as shown in Figure 1b and c; PNVCL-L and PNVCL-H presented LCST values of $\sim 34^{\circ} \mathrm{C}$ and $32^{\circ} \mathrm{C}$, respectively. This reduction of the LCST with the MW can be explained according to the Flory-Huggins miscibility behavior, where PNVCL exhibits the classical phase change in water (type I) and where the critical point in the 
a
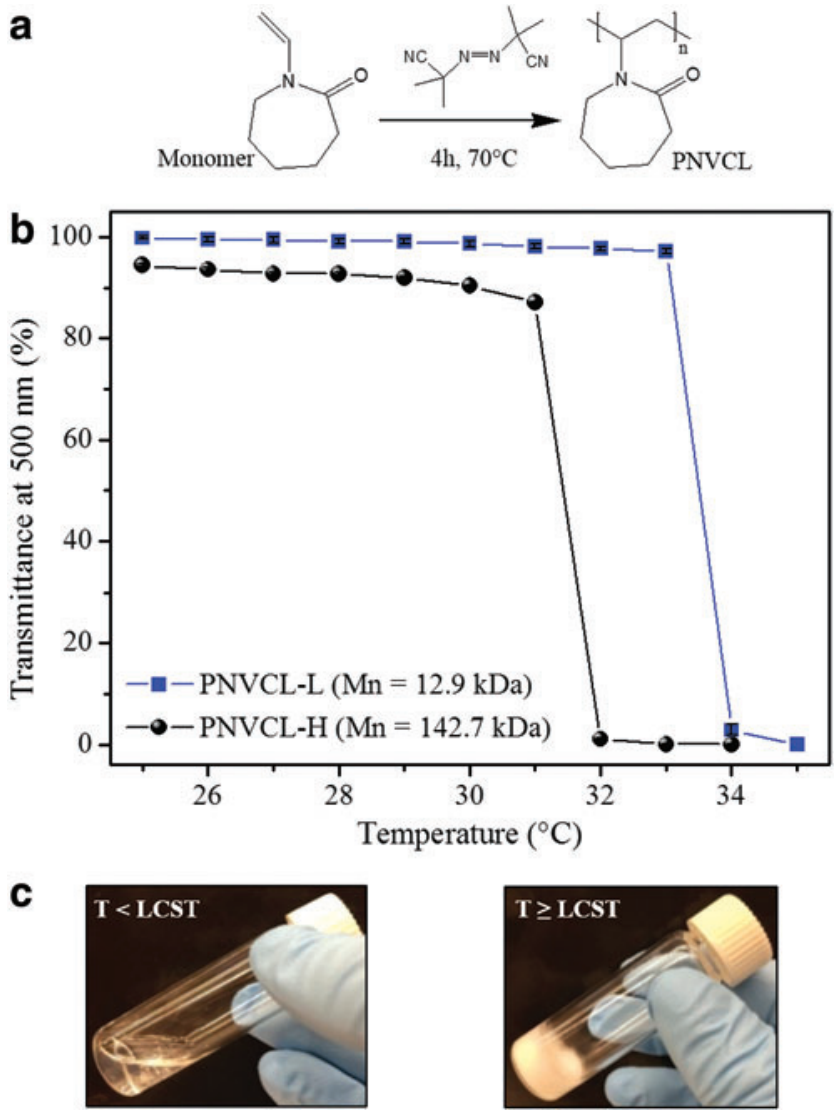

FIG. 1. Representation of the radical polymerization of PNVCL (a). The percent transmittance (at a wavelength of $500 \mathrm{~nm}$ ) as a variation of temperature of PNVCL suspensions $(1 \% \mathrm{w} / \mathrm{v})$ with different molecular weights (b). Images of the transition of a PNVCL-L suspension from transparent to opaque when below and above the LCST, respectively (c). LCST, lower critical solution temperature; PNVCL, poly(N-vinylcaprolactam); PNVCL-L, PNVCL lower. Color images available online at www.liebertpub.com/tea

phase diagram shifts to LCST values with the increase of polymer chain length and concentration. ${ }^{39,40}$

The viscoelastic properties of the hydrogels were evaluated by monitoring the storage and loss moduli $\left(\mathrm{G}^{\prime}, \mathrm{G}^{\prime \prime}\right.$, respectively) as a function of temperature and time (Fig. 2). Increasing the system temperature from $25^{\circ} \mathrm{C}$ to $37^{\circ} \mathrm{C}$ resulted in higher mechanical properties for all polymer suspensions; this is a result of the transition phase and the formation of the globule phase. By changing the concentration of the PNVCL-L suspension from $10 \%$ to $30 \%$ (Fig. 2a), higher mechanical properties were observed, where $G^{\prime \prime}$ was greater than $\mathrm{G}^{\prime}$ for all concentrations, a condition indicative of viscous liquid materials and where $\mathrm{G}^{\prime \prime}$ reached up to $125 \mathrm{~Pa}$. For PNVCL-H, the concentration varied from 5\% to $20 \%$ (Fig. 2b), due to the insolubility of the polymer in PBS at higher concentrations. For all concentrations, $\mathrm{G}^{\prime}$ was greater than $\mathrm{G}^{\prime \prime}$, a condition indicative of elastic hydrogel formation, ${ }^{2,41}$ where $\mathrm{G}^{\prime}$ reached up to $\sim 1.36 \mathrm{kPa}$. Comparing both polymer systems above the LCST, PNVCL-L cannot be considered a gel since $\mathrm{G}^{\prime \prime}>\mathrm{G}^{\prime}$. However, with the increase of the temperature and association of the PNVCL-L polymer chains with further phase separation, PNVCL-L acquires a "gel-like" behavior compared to the same material at room temperature. ${ }^{24,42}$ On the contrary, PNVCL-H reached the gel point $\left(G^{\prime}>G^{\prime \prime}\right)$ at LCST for all investigated concentrations. Different MWs between PNVCL-L and PNVCL-H explain these distinct mechanical properties, since longer chains result in more entanglement, which increases the viscosity and the elastic energy stored. ${ }^{43}$

Two intermediate concentrations for PNVCL-L (20\% w/v) and PNVCL-H (10\% w/v) were then chosen (based on their mechanical properties and their solubility in medium) for further investigation in vitro and in vivo. These studies required fast gelation time and increased mechanical properties from the polymer suspensions to prevent the diffusion of the material away from the injection site and to ensure the stability of the hydrogel. ${ }^{44}$ To simulate how the mechanical properties of PNVCL hydrogels respond to the temperature stimuli imposed by physiological conditions, PNVCL-L $(20 \% \mathrm{w} / \mathrm{v})$ and PNVCL-H $(10 \%$ w/v $)$ maintained initially at $25^{\circ} \mathrm{C}$ were heated to $37^{\circ} \mathrm{C}$ (Fig. 2c). Both materials showed that the greatest $\mathrm{G}^{\prime}$ and $\mathrm{G}^{\prime \prime}$ were reached in $<60 \mathrm{~s}$, the same time needed for the rheometer to stabilize to $37^{\circ} \mathrm{C}$. This result indicates that the response of PNVCL suspensions to temperature stimuli should be almost immediate when presented into a physiological environment. Unlike injectable hydrogels formed by chemical reactions that can result in local toxicity and slow gelation, ${ }^{13,44}$ PNVCL materials exhibited tunable mechanical properties and fast response to temperature stimuli without the need for additional cross-linkers or copolymerization.

\section{Cytocompatibility of PNVCL}

Some thermosensitive hydrogels have showed cytotoxic effects, depending on their MW and concentration of polymer. ${ }^{25,44-46}$ The cytotoxicity related to the MW has been associated with hydrogels with shorter polymer chains, in particular, those that can penetrate the cell membrane, altering cell activity. In addition, in the case of polymers with higher MW, cytotoxic effects are thought to be related to the reduction of the diffusion of nutrients and oxygen to the cells, leading to cell death. ${ }^{46} \mathrm{CHs}$ and MSCs were analyzed in the presence of PNVCL-L and PNVCL-H at a range of polymer concentrations in basal media $(0.001-1 \mathrm{mg} / \mathrm{mL})$. Cells were seeded in a 96-well plate and, subsequently, incubated for $24 \mathrm{~h}$ with polymer suspension, as represented in Figure $3 \mathrm{a}$. $\mathrm{CH}$ and MSC viability was then assessed using the $\mathrm{AB}$ assay (Fig 3b, c, respectively). Comparing the fluorescence readouts of cells incubated in the presence of polymer with cells in basal media enabled an estimate of viability. A high cell viability of $100 \%$ was observed for PNVCL-L and PNVCL-H for all concentrations investigated, without significant differences between groups, with the exception of PNVCL-H at $1 \mathrm{mg} / \mathrm{mL}$ for $\mathrm{CHs}$ and 0.01 and $1 \mathrm{mg} / \mathrm{mL}$ for MSCs, as well as PNVCL-L at $1 \mathrm{mg} / \mathrm{mL}$ for MSCs. Each of these conditions showed a significant increase in the cell viability, which may be related to cell proliferation or also to a higher metabolic activity of cells in the presence of polymer. ${ }^{47}$ By observing no differences between the cell activity and the presence of PNVCL-H or PNVCL-L in several cases, however, we determined that the previously suggested effects of low versus high MW on cell viability were not observed with these polymers and that cell viability was maintained in the presence of either polymer. 

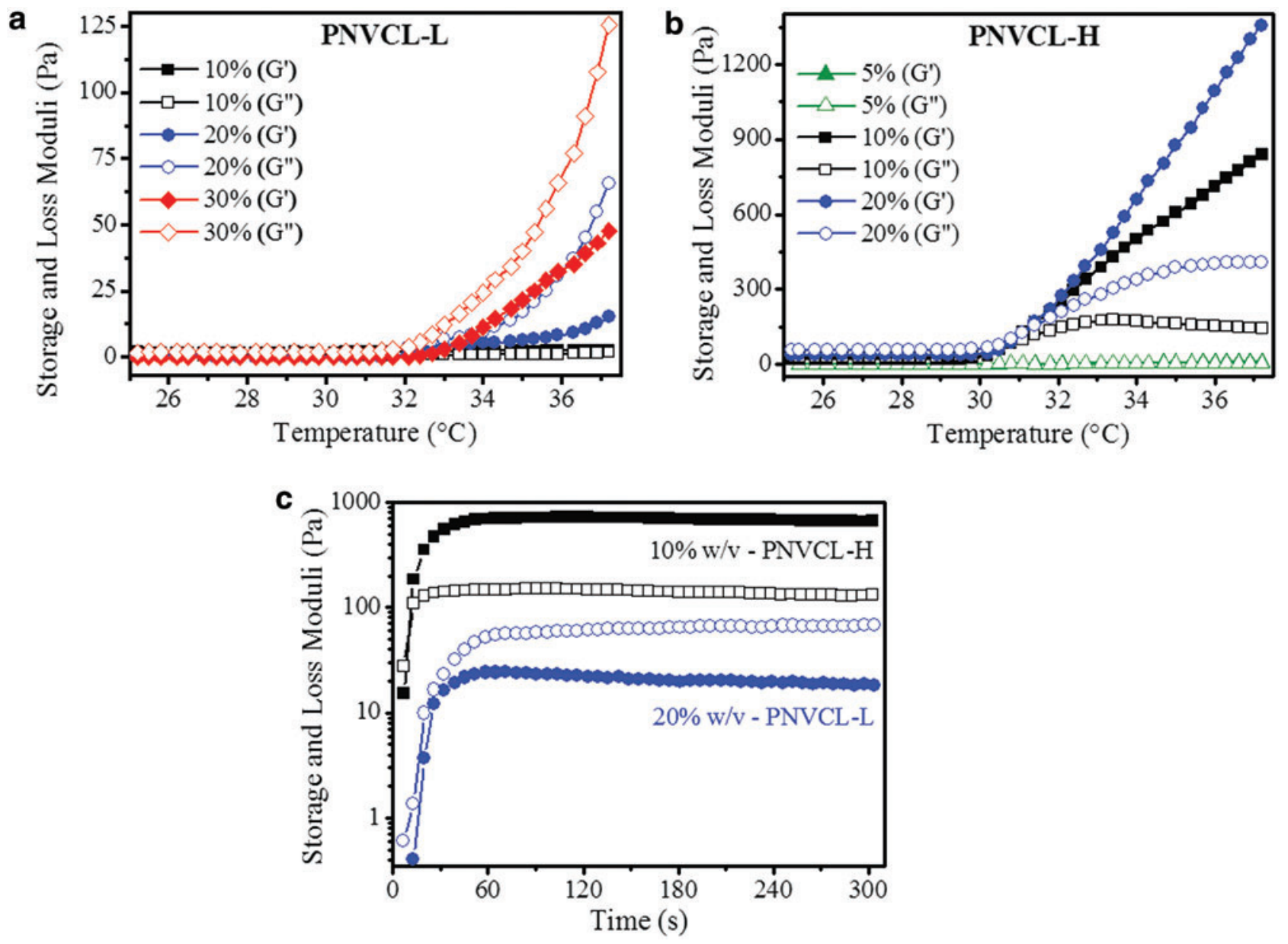

FIG. 2. Variation of storage $\left(\mathrm{G}^{\prime}\right.$, solid $)$ and loss $\left(\mathrm{G}^{\prime \prime}\right.$, open $)$ moduli with temperature of PNVCL-L from $10 \%$ to $30 \%$ w/v (a) and PNVCL-H from $5 \%$ to $20 \% \mathrm{w} / \mathrm{v}$ (b). Increase of $\mathrm{G}^{\prime}$ and $\mathrm{G}^{\prime \prime}$ with time for PNVCL-L (20\% w/v) and PNVCL-H (10\% $\mathrm{w} / \mathrm{v})$ hydrogels, starting at room temperature and increasing to $37^{\circ} \mathrm{C}$, indicated by the temperature profile with time (c). PNVCL-H, PNVCL higher. Color images available online at www.liebertpub.com/tea

\section{Three-dimensional cell viability and in vitro studies}

To investigate cell behavior in 3D scaffolds composed of these materials, $\mathrm{CHs}$ and MSCs were encapsulated in PNVCL-L (20\% w/v) and PNVCL-H (10\% w/v) by resuspending cell pellets in the hydrogel suspensions as shown in Figure 4a. These suspensions were injected into molds using three different hypodermic needle gauges and incubated at $37^{\circ} \mathrm{C}$. Cell viability was determined using a LiveDead Cell Staining Kit after 0 (after injection into molds) and 3 days of culture in chondrogenic media (Fig. 4b). The encapsulation of cells in thermosensitive polymers is dictated according to the temperature. At physiological conditions above the LCST, polymer hydrophobic interactions stabilize the gel and the resulting cell distribution. ${ }^{48}$ However, if the system is brought to temperatures below LCST, PNVCL polymer chains will swell with predominant hydrophilic interactions, which may disrupt cell distributions at early times before matrix is produced.

For PNVCL-L, CH viability remained $>80 \%$ up to day 3 , without significant differences among the days and needle gauge used. Only a slight reduction was observed for the cell viability at day 0 and with $27 \mathrm{G}$ needle use, most likely due to the mechanical shear on cells during the injection through a smaller needle. ${ }^{41}$ In contrast, CH-laden PNVCL-H hydrogels had viability $>90 \%$ at day 0 and $\sim 75 \%$ at day 3 . This reduction may be associated with the tendency of thermosensitive polymers with higher MW to form a denser hydrogel, which can reduce the diffusion of nutrients and oxygen. ${ }^{46,49}$ In addition, no significant differences in viability were observed for different needle sizes. In this way, regardless of the MW and mechanical properties of PNVCL-L and PNVCL-H, these hydrogels effectively delivered encapsulated viable cells independent of the needle size used.

Figure $4 \mathrm{c}$ and $\mathrm{d}$ shows live/dead stained images of $\mathrm{CHs}$ and MSCs encapsulated in the hydrogels, respectively, after injection with a $21 \mathrm{G}$ needle. Viable $\mathrm{CHs}$ were homogenously distributed in the 3D system, while MSC-laden PNVCL-L gels exhibited some cell agglomerations, making them difficult to quantify. These differences in cell distribution in the PNVCL-L matrix suggest the influence of the cell-scaffold interaction on morphology. ${ }^{50}$ Differences in contractile behavior of cell types also influence their interaction with external mechanical forces imposed by polymeric substrates with specific stiffnesses. ${ }^{51,52}$ 
a
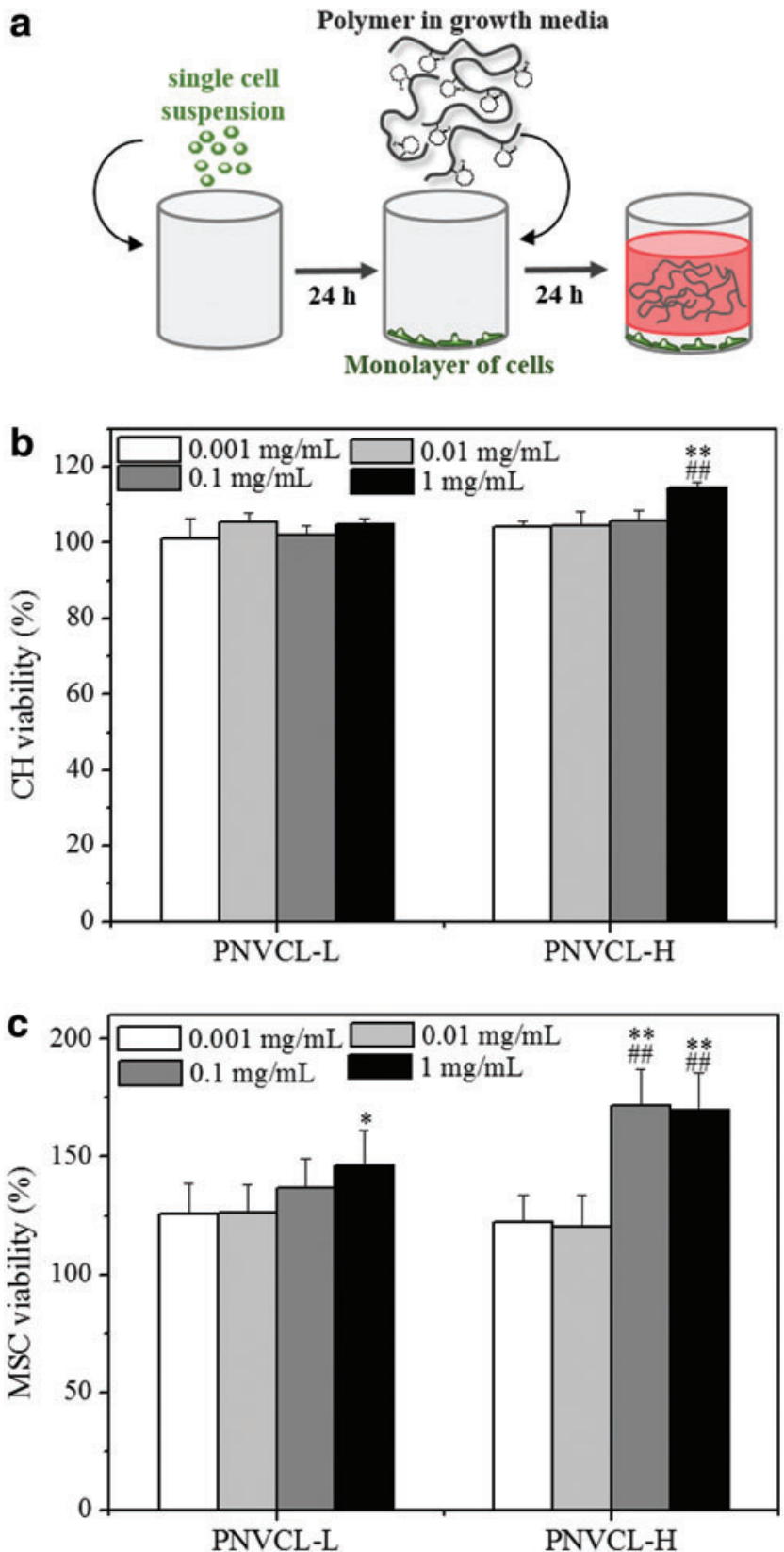

FIG. 3. Schematic representation of the $2 \mathrm{D}$ system used for cytotoxicity studies. A monolayer of $\mathrm{CHs}$ was formed on the bottom of the well and then incubated with polymer suspensions in growth media (a). CH (b) or MSC (c) viability was assessed by Alamar Blue assay after 1 day for PNVCL-L and PNVCL-H at different polymer concentrations $(0.001-1 \mathrm{mg} / \mathrm{mL})$. ****Indicate statistical significance $(p<0.05$ and $p<0.01$, respectively) versus corresponding hydrogel with concentration of $0.001 \mathrm{mg} / \mathrm{mL}$. \#\#Indicates statistical significance $(p<0.01)$ versus the cell viability of PNVCL-L with the same polymer concentration. $\mathrm{CH}$, chondrocyte; MSC, mesenchymal stem cell. Color images available online at www.liebertpub.com/tea

At day 3, the number of cells was reduced compared to day 0 for both systems of encapsulated hydrogels. This could be an unavoidable consequence of media changes, where hydrogels were temporarily exposed to room temperature conditions. Given their reversible sol-gel transition with temperature, this could possibly lead to the release of cells from the materials. This reduction in cell number after 3 days of cell culture was less pronounced for the PNVCL$\mathrm{H}$, where a higher MW resulted in greater entanglements of polymer chains, forming a dense hydrogel that could better retain the encapsulated cells. ${ }^{53}$ In this context, encapsulated PNVCL-H hydrogels showed a better cell retention during in vitro studies than PNVCL-L.

Scaffolds intended for cartilage repair/regeneration should maintain the phenotype of $\mathrm{CHs}$ and enable cellular function in 3D. ${ }^{10,54} \mathrm{CH}$-laden hydrogels in chondrogenic media were cultured in vitro for 4 and 8 weeks, and the GAG and collagen contents per construct at each timepoint were analyzed by DMMB and OHP assays, respectively, as shown in Figure 5. MSC cultures were not investigated further at this point, due to the aggregation observed. Similar GAG content was observed for both hydrogels after 4 and 8 weeks with only minor differences, with up to $21 \mu \mathrm{g}$ GAG per sample as depicted in Figure 5a. PNVCL-H had a higher amount of GAG than PNVCL-L after 4 weeks, and similar contents were observed after 8 weeks for both hydrogels. Increasing the culture time led to higher amounts of GAG content in PNVCL-L constructs and reduced content in PNVCL-H gels. The similar amounts of GAG produced and retained in both materials at specific timepoints may be related to the release of cells to the media that was periodically replaced, as described above.

In contrast, the collagen content produced by $\mathrm{CHs}$ was dependent on the encapsulated matrix. As shown in Figure 5b, CH-laden PNVCL-L gels yielded up to 3.5-fold more collagen per construct than PNVCL-H gels after both 4 and 8 weeks. Although a slight increase of collagen for PNVCL-L was observed at 8 weeks compared to 4 weeks, no statistical difference was observed between timepoints for both hydrogels. These results suggest that PNVCL hydrogels with different MWs support cartilage matrix production and maintain the phenotype of $\mathrm{CHs}$ in $3 \mathrm{D}$ culture in vitro. The ability of PNVCL-L to support more collagen production than PNVCL-H may be related to differences in their mechanical properties. Soft hydrogels have been shown to improve matrix production by $\mathrm{CHs}$, induced by better nutrient diffusion, distribution of newly synthesized cartilage matrix, and differences in cell-cell interactions and distribution. ${ }^{9,55}$

\section{Biochemical and histological analyses of hydrogels subcutaneously injected into nude rats}

To investigate the stability of thermosensitive PNVCL and its ability to support neocartilage formation in vivo, $\mathrm{CH}-$ laden hydrogels were subcutaneously injected into nude rats. At subsequent time intervals, implants were removed from the subcutaneous space and analyzed as shown in Figure 6. Implants were stable throughout the 8-week study and remained localized at the injection site, with some formation of a fibrous capsule. Figure $6 \mathrm{a}$ also showed that implants of PNVCL-L were more spread and flatter than PNVCL-H implants, which presented a more compact shape, likely due to variations in material viscosity.

As shown in Figure 6b, no significant differences in GAG content per construct were observed for PNVCL-L and PNVCL-H at 4 and 8 weeks. Although similar behavior was 
a

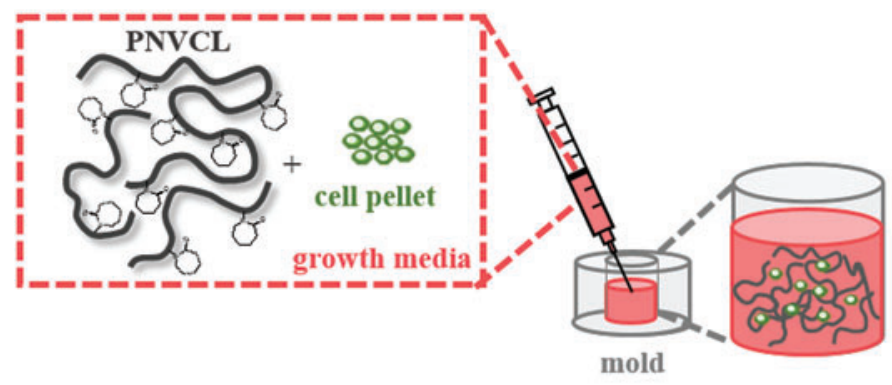

C
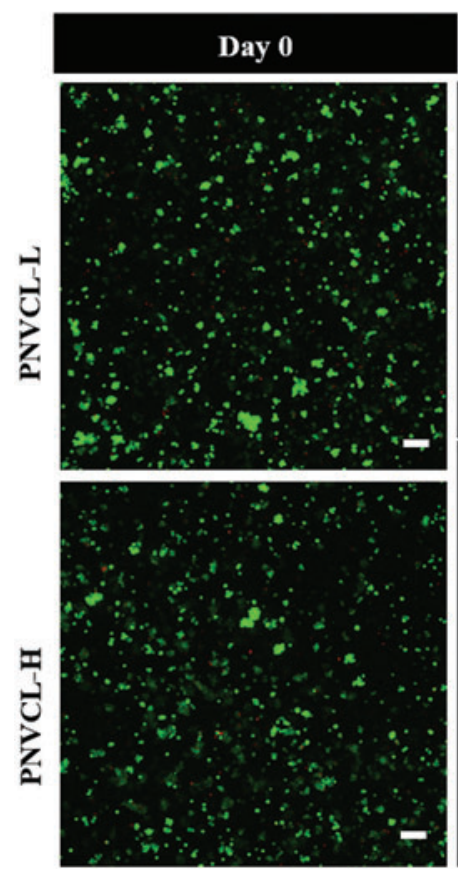

Chondrocytes
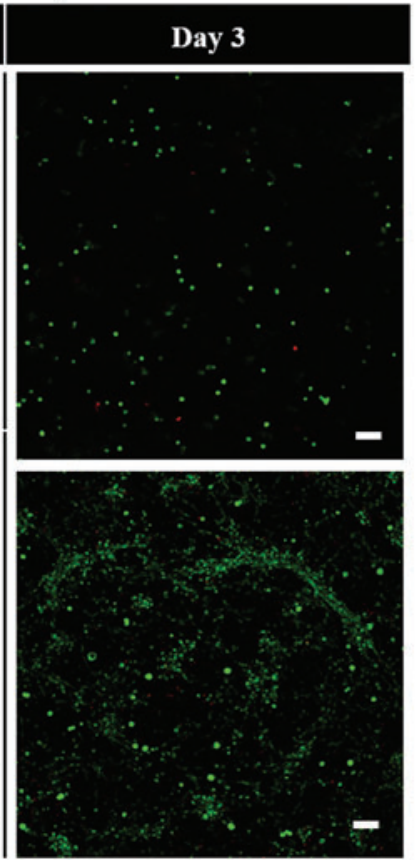

b

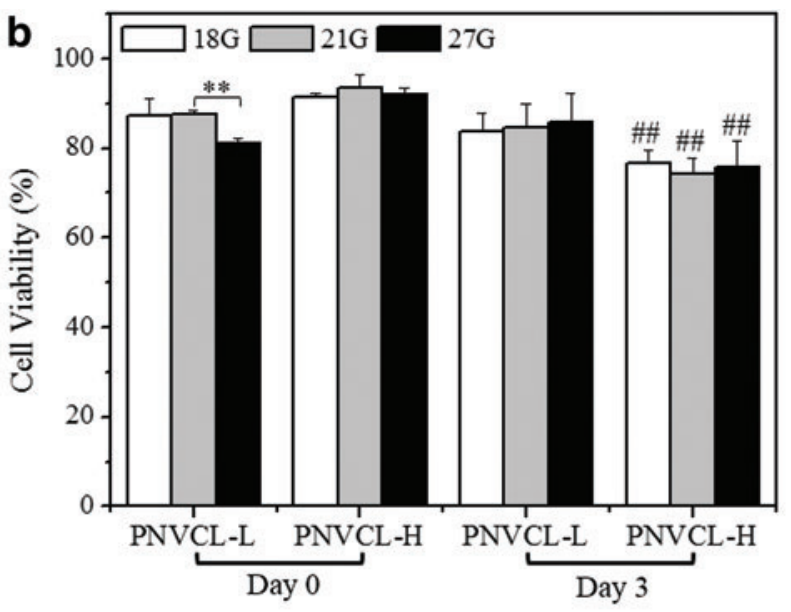

d
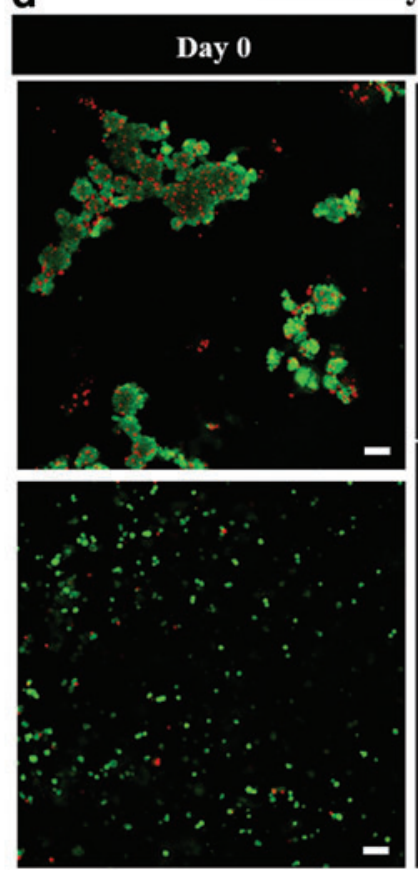

Mesenchymal stem cells

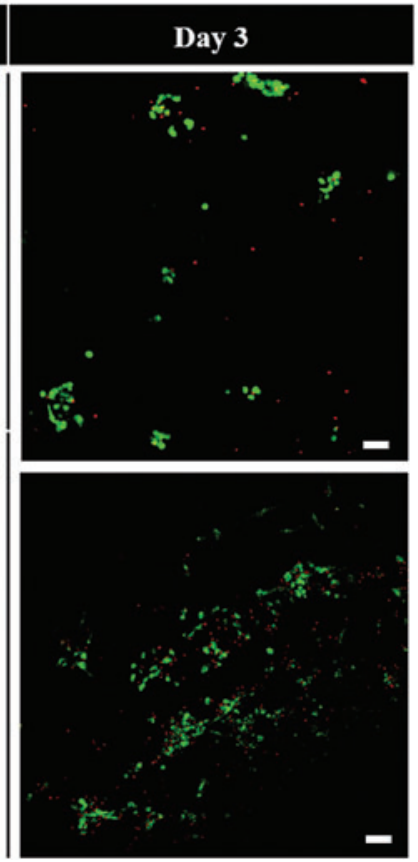

FIG. 4. Schematic representation of the 3D system for cell encapsulation, injection in a polydimethylsiloxane mold, and incubation at $37^{\circ} \mathrm{C}$ (a). $\mathrm{CH}$ viability on the day of preparation (day 0) and after 3 days (day 3) of encapsulation in PNVCL-L $(20 \% \mathrm{w} / \mathrm{v})$ and PNVCL-H (10\% w/v) injected with three needles of size (18G, 21G, and 27G) (b). Live/dead imaging (live cells-green; dead cells-red) of CH-laden (c) and MSC-laden (d) hydrogels injected with a needle of $21 \mathrm{G}$, at days 0 and 3 (scale bars, $100 \mu \mathrm{m})$. **Indicates significance $(p<0.01)$ between groups $21 \mathrm{G}$ and $27 \mathrm{G}$ for PNVCL-L. ${ }^{\# \#}$ Indicates significance $(p<0.01)$ versus the cell viability of PNVCL-H at day 0 for each gauge size. 3D, three-dimensional. Color images available online at www.liebertpub.com/tea

observed during in vitro studies, a much greater production of GAG (up to $1245 \mu \mathrm{g}$ per sample) was attained in vivo, especially in the case of PNVCL-L injections, which generally accumulated greater GAG than PNVCL-H implants. In addition, a time-dependent increase of GAG content per construct was observed with both PNVCL-L and PNVCL-H implants, exhibiting an increase of 1.5 and 1.9-fold, respectively, after 8 weeks compared to 4 weeks. Better results in vivo than in vitro can be attributed to the lack of destabilization of the system due to fluctuations in temperature during handling for in vitro culture, which can interfere in the retention of cells and synthesized cartilage components in the hydrogels. Finally, Figure $6 \mathrm{c}$ shows the collagen content in constructs after 4 and 8 weeks, which followed the same trends as were observed in the in vitro analyses, including the ratio of collagen produced by PNVCL-L and PNVCL-H between the two timepoints. Overall, taking into account the injected volume of hydrogel used for each condition studied, significant increases of these cartilage components were observed in CH-hydrogels that were subcutaneously injected compared to those cultured in vitro.

To evaluate the distribution of synthesized GAGs and collagen types I and II, implant sections were stained for these cartilage components and imaged. The intensity of 
FIG. 5. Amount of GAG (a) and total collagen (b) per sample $(\mathrm{V}=50 \mu \mathrm{L})$ of CH-laden PNVCL-L $(20 \% \mathrm{w} / \mathrm{v})$ and PNVCL-H (10\% w/v) hydrogels after 4 and 8 weeks of in vitro culture. **Indicates significance $(p<0.01)$ between 4 and 8 weeks for the same polymer. ${ }^{\# \#}$ Indicates significance $(p<0.01)$ between PNVCL-L and PNVCL-H at 4 or 8 weeks. GAG, glycosaminoglycan.

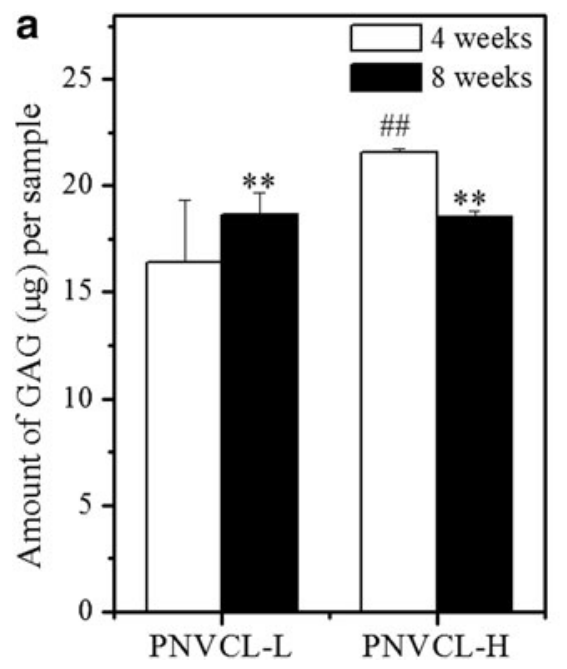

staining was quantified using ImageJ. Figure $7 \mathrm{a}$ and $\mathrm{d}$ shows a time-dependent increase in Alcian blue staining compared to the control group (acellular gels after 4 weeks of implantation). PNVCL-L constructs exhibited more evenly distributed Alcian blue staining than PNVCL-H, although no statistical differences were observed between their staining intensities. Articular cartilage is comprised mainly of type II collagen and, in small or negligible amounts, type I collagen ${ }^{56}$; immunohistochemical staining against type I and II collagen was used in this study to identify the majority component that accumulated in the $\mathrm{CH}$-laden hydrogels. Increases in Col II staining over time can be observed evenly distributed in both PNVCL-L and PNVCL-H constructs in Figure $7 \mathrm{~b}$ and e compared to control groups. In contrast, Figure 7c and f shows comparable Col I staining among the control groups and all implants after 4 and 8 weeks. A slightly higher intensity was observed at 8 weeks in PNVCL-L gels, which could be attributed to the diffusion of Col I from the fibrous capsule that formed around the implant. When comparing the histology data with biochemical analysis, it is possible to note that although $\mathrm{CH}$-laden PNVCL-H showed similar collagen content after 4 and 8 weeks, an intense and time-dependent increase of Col II staining was observed.

Despite some studies with injectable hydrogels for cartilage tissue engineering having shown neocartilage formation, ${ }^{2,57-59}$ some characteristics such as long gelation times, sample instability, and poor matrix production can be noted. ${ }^{11,32,60-63}$ In this study, in the case of the thermosensitive polymer PNVCL, hydrogels were produced by simple methods with distinct mechanical properties and fast response to temperature stimuli. They could also encapsulate viable $\mathrm{CHs}$ and support neocartilage formation after in vitro culture
FIG. 6. Images of the subcutaneous implants after 4 and 8 weeks (scale bars, $1 \mathrm{~cm}$ ) (a). Amount of GAG (b) and collagen (c) per sample $(\mathrm{V}=200 \mu \mathrm{L})$ of $\mathrm{CH}$-laden PNVCL-L (20\% w/v) and PNVCL-H (10\% w/v) hydrogels after 4 and 8 weeks of in vivo culture. $* * *$ Indicate significance $(p<0.05$ and $p<0.01$, respectively) between 4 and 8 weeks for the same polymer. "\#\# Indicates significance $(p<0.01)$ between PNVCL-L and PNVCL-H at 4 or 8 weeks. Color images available online at www.liebertpub.com/ tea a
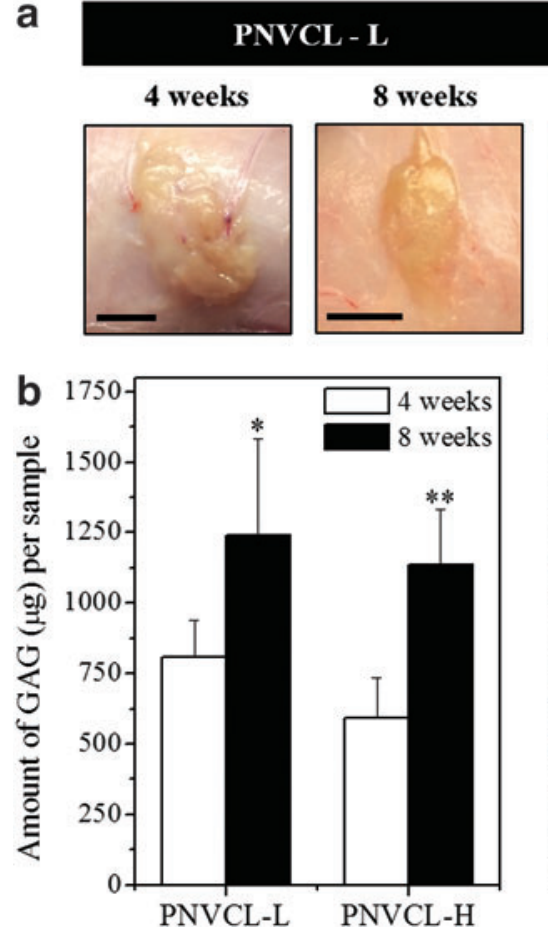

PNVCL - H
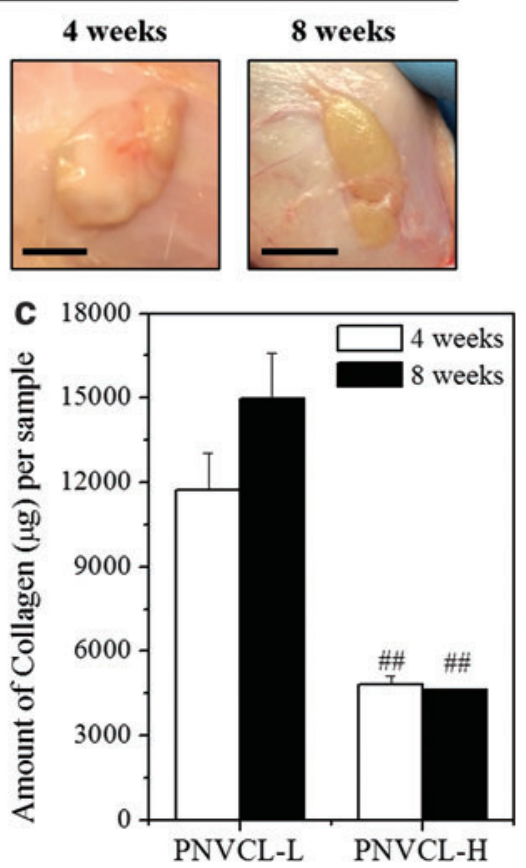
a
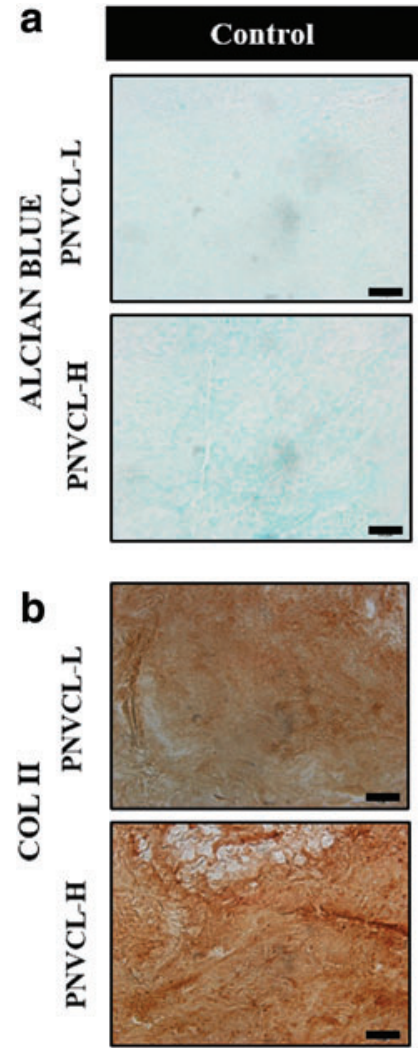

C

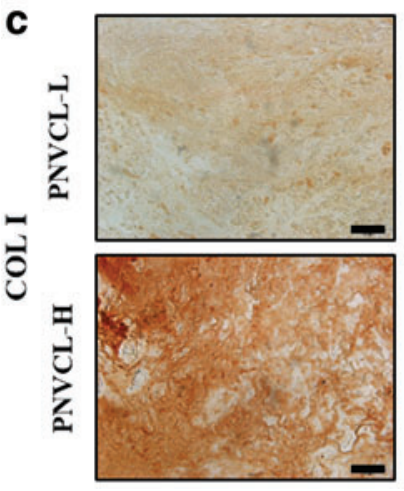

4 weeks
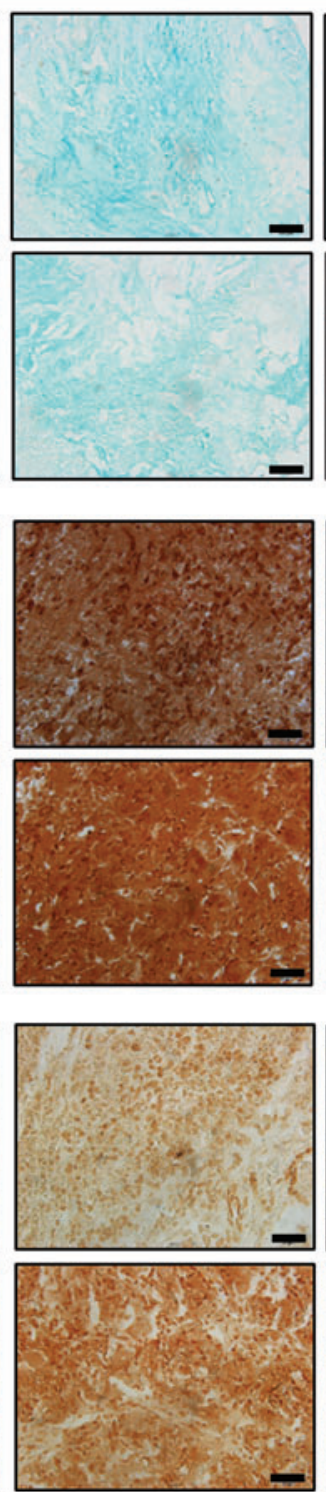

8 weeks
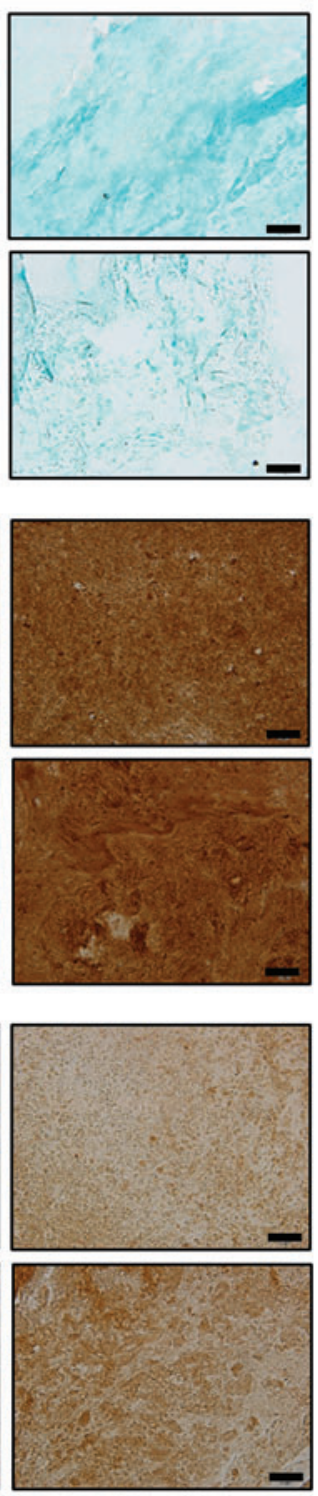

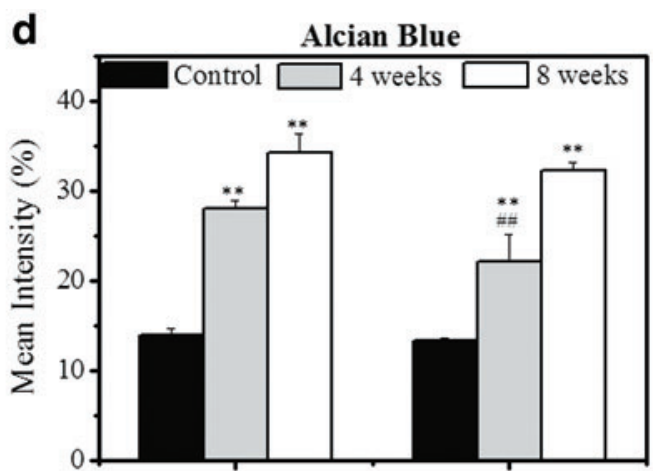

PNVCL-L

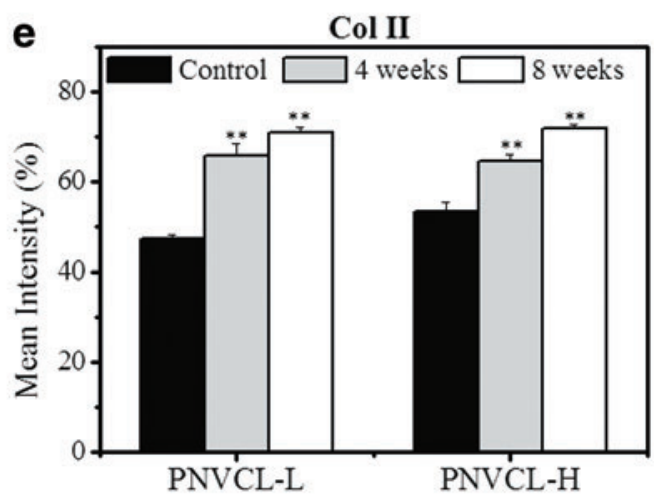

f

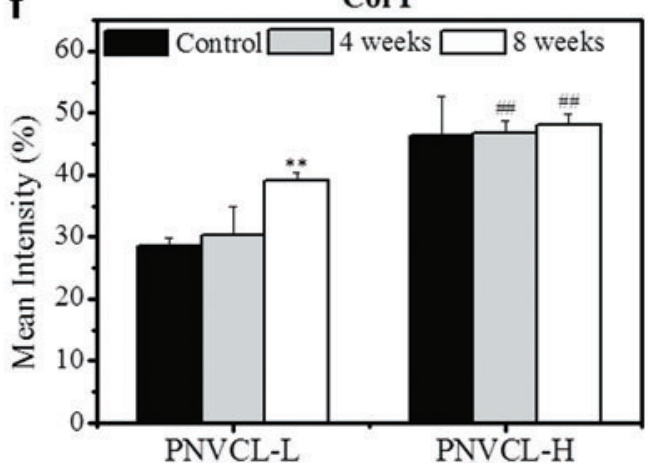

FIG. 7. Images (a-c) and quantification (d-f) for Alcian blue (top) and immunohistochemical staining of type II collagen (Col II, middle) and type I collagen (Col I, bottom) of encapsulated CHs or acellular control (4 weeks) in PNVCL-L (20\% w/v) and PNVCL-H (10\% w/v) hydrogels after 4 and 8 weeks of subcutaneous implantation in rats. Scale bars for (a) are $100 \mu \mathrm{m}$ and for $(\mathbf{b}, \mathbf{c})$ are $50 \mu \mathrm{m}$. **** Indicate significance $(p<0.05$ and $p<0.01$, respectively) versus control groups

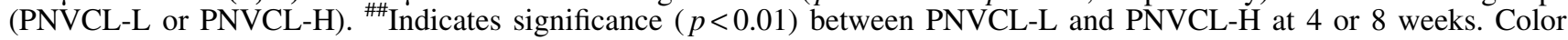
images available online at www.liebertpub.com/tea

and after in vivo subcutaneous injections in nude rats for 8 weeks.

\section{Conclusions}

In the present study, thermosensitive injectable hydrogels of PNVCL with tunable mechanical properties and fast response to temperature stimuli showed great potential for application to cartilage repair. PNVCL hydrogels with different MWs supported viable cell encapsulation of $\mathrm{CHs}$ and MSCs, as well as cartilage matrix production, maintaining the phenotype of $\mathrm{CHs}$ during 3D culture in vitro. Furthermore, subcutaneous injections in nude rats resulted in stable
CH-laden hydrogel implants that produced cartilage ECM components in much greater amounts than with in vitro studies. Cell-laden PNVCL-L constructs with lower mechanical properties also showed increased ECM accumulation compared to those with PNVCL-H, possibly due to superior nutrient diffusion and more favorable mechanics for $\mathrm{CH}$ function. Therefore, PNVCL hydrogels show promise as scaffolds for cartilage tissue engineering.

\section{Acknowledgments}

This work was supported by São Paulo Research Foundation (FAPESP) grants 2015/07185-1 and 2013/25663-2, 
CEPID/CDMF (FAPESP) grant 2013/07296-2, and the National Institutes of Health (R01 EB008722) and a National Science Foundation Graduate Research Fellowship (to M.K.).

\section{Disclosure Statement}

No competing financial interests exist.

\section{References}

1. Chung, C., and Burdick, J.A. Engineering cartilage tissue Adv Drug Del Rev 60, 243, 2008.

2. Ren, K., He, C., Xiao, C., Li, G., and Chen, X. Injectable glycopolypeptide hydrogels as biomimetic scaffolds for cartilage tissue engineering. Biomaterials 51, 238, 2015.

3. Erickson, I.E., Huang, A.H., Sengupta, S., Kestle, S., Burdick, J.A., and Mauck, R.L. Macromer density influences mesenchymal stem cell chondrogenesis and maturation in photocrosslinked hyaluronic acid hydrogels. Osteoarthritis Cartilage 17, 1639, 2009.

4. Makris, E.A., Gomoll, A.H., Malizos, K.N., Hu, J.C., and Athanasiou, K.A. Repair and tissue engineering techniques for articular cartilage. Nat Rev Rheumatol 11, 21, 2015.

5. Sivashanmugam, A., Arun Kumar, R., Vishnu Priya, M., Nair, S.V., and Jayakumar, R. An overview of injectable polymeric hydrogels for tissue engineering. Eur Polym J 72, 543, 2015.

6. Temenoff, J.S., and Mikos, A.G. Review: tissue engineering for regeneration of articular cartilage. Biomaterials 21, 431, 2000.

7. Huang, B.J., Hu, J.C., and Athanasiou, K.A. Cell-based tissue engineering strategies used in the clinical repair of articular cartilage. Biomaterials 98, 1, 2016.

8. Bian, L., Guvendiren, M., Mauck, R.L., and Burdick, J.A. Hydrogels that mimic developmentally relevant matrix and N-cadherin interactions enhance MSC chondrogenesis. Proc Natl Acad Sci U S A 110, 10117, 2013.

9. Bian, L., Hou, C., Tous, E., Rai, R., Mauck, R.L., and Burdick, J.A. The influence of hyaluronic acid hydrogel crosslinking density and macromolecular diffusivity on human MSC chondrogenesis and hypertrophy. Biomaterials 34, 413, 2013.

10. Kim, I.L., Mauck, R.L., and Burdick, J.A. Hydrogel design for cartilage tissue engineering: a case study with hyaluronic acid. Biomaterials 32, 8771, 2011.

11. Park, K.M., Lee, S.Y., Joung, Y.K., Na, J.S., Lee, M.C., and Park, K.D. Thermosensitive chitosan-pluronic hydrogel as an injectable cell delivery carrier for cartilage regeneration. Acta Biomater 5, 1956, 2009.

12. Jin, R., Moreira Teixeira, L.S., Krouwels, A., Dijkstra, P.J., van Blitterswijk, C.A., Karperien, M., and Feijen, J. Synthesis and characterization of hyaluronic acidpoly(ethylene glycol) hydrogels via Michael addition: an injectable biomaterial for cartilage repair. Acta Biomater 6, 1968, 2010.

13. Nguyen, Q.V., Huynh, D.P., Park, J.H., and Lee, D.S. Injectable polymeric hydrogels for the delivery of therapeutic agents: a review. Eur Polym J 72, 602, 2015.

14. Yang, J.-A., Yeom, J., Hwang, B.W., Hoffman, A.S., and Hahn, S.K. In situ-forming injectable hydrogels for regenerative medicine. Prog Polym Sci 39, 1973, 2014.

15. Desai, R.M., Koshy, S.T., Hilderbrand, S.A., Mooney, D.J., and Joshi, N.S. Versatile click alginate hydrogels crosslinked via tetrazine-norbornene chemistry. Biomaterials 50, 30, 2015.
16. Guvendiren, M., and Burdick, J.A. Stiffening hydrogels to probe short- and long-term cellular responses to dynamic mechanics. Nat Commun 3, 792, 2012.

17. Yang, T., Ji, R., Deng, X.-X., Du, F.-S., and Li, Z.-C. Glucoseresponsive hydrogels based on dynamic covalent chemistry and inclusion complexation. Soft Matter 10, 2671, 2014.

18. Klouda, L. Thermoresponsive hydrogels in biomedical applications: a seven-year update. Eur J Pharm Biopharm 97, Part B, 338, 2015.

19. Liu, X.J., Li, H.Q., Zhang, B.Y., Wang, Y.J., Ren, X.Y., Guan, S., and Hui Gao, G. Highly stretchable and tough $\mathrm{pH}$-sensitive hydrogels with reversible swelling and recoverable deformation. RSC Adv 6, 4850, 2016.

20. Rodell, C.B., Kaminski, A.L., and Burdick, J.A. Rational design of network properties in guest-host assembled and shear-thinning hyaluronic acid hydrogels. Biomacromolecules 14, 4125, 2013.

21. Rodell, C.B., Mealy, J.E., and Burdick, J.A. Supramolecular guest-host interactions for the preparation of biomedical materials. Bioconjug Chem 26, 2279, 2015.

22. Ponce-Vargas, S.M., Cortez-Lemus, N.A., and LiceaClaveríe, A. Preparation of poly(N-vinylcaprolactam) (NVCL) and statistical copolymers of NVCL with variable cloud point temperature by using a trithiocarbonate RAFT agent. Macromol Symp 325-326, 56, 2013.

23. Ramos, J., Imaz, A., and Forcada, J. Temperature-sensitive nanogels: poly(N-vinylcaprolactam) versus poly $(\mathrm{N}-$ isopropylacrylamide). Polym Chem 3, 852, 2012.

24. Klouda, L., and Mikos, A.G. Thermoresponsive hydrogels in biomedical applications. Eur J Pharm Biopharm 68, 34, 2008.

25. Vihola, H., Laukkanen, A., Valtola, L., Tenhu, H., and Hirvonen, J. Cytotoxicity of thermosensitive polymers poly(N-isopropylacrylamide), poly(N-vinylcaprolactam) and amphiphilically modified poly( $\mathrm{N}$-vinylcaprolactam). Biomaterials 26, 3055, 2005.

26. Liang, X., Kozlovskaya, V., Chen, Y., Zavgorodnya, O., and Kharlampieva, E. Thermosensitive multilayer hydrogels of poly(N-vinylcaprolactam) as nanothin films and shaped capsules. Chem Mater 24, 3707, 2012.

27. Cortez-Lemus, N.A., and Licea-Claverie, A. Poly(Nvinylcaprolactam), a comprehensive review on a thermoresponsive polymer becoming popular. Prog Polym Sci 53, 1, 2016.

28. Rejinold, N.S., Chennazhi, K.P., Nair, S.V., Tamura, H., and Jayakumar, R. Biodegradable and thermo-sensitive chitosan-g-poly(N-vinylcaprolactam) nanoparticles as a 5fluorouracil carrier. Carbohydr Polym 83, 776, 2011.

29. Markvicheva, E.A., Tkachuk, N.E., Kuptsova, S.V., Dugina, T.N., Strukova, S.M., Kirssh, Y.E., Zubov, V.P., and Rumish, L.D. Stabilization of proteases by entrapment in a new composite hydrogel. Appl Biochem Biotechnol 61, 75, 1996.

30. Shakya, A.K., Holmdahl, R., Nandakumar, K.S., and Kumar, A. Polymeric cryogels are biocompatible, and their biodegradation is independent of oxidative radicals. J Biomed Mater Res A 102, 3409, 2014.

31. Srivastava, A., and Kumar, A. Thermoresponsive poly(Nvinylcaprolactam) cryogels: synthesis and its biophysical evaluation for tissue engineering applications. J Mater Sci Mater Med 21, 2937, 2010.

32. Lynch, B., Crawford, K., Baruti, O., Abdulahad, A., Webster, M., Puetzer, J., Ryu, C., Bonassar, L.J., and Mendenhall, J. The effect of hypoxia on thermosensitive poly(N-vinylcaprolactam) hydrogels with tunable mechanical integrity for cartilage tissue 
engineering. J Biomed Mater Res B Appl Biomater 2016; DOI: 10.1002/jbm.b.33705.

33. Medeiros, S.F., Barboza, J.C.S., Ré, M.I., Giudici, R., and Santos, A.M. Solution polymerization of N-vinylcaprolactam in 1,4-dioxane. Kinetic dependence on temperature, monomer, and initiator concentrations. J Appl Polym Sci 118, 229, 2010.

34. Kim, M., Erickson, I.E., Choudhury, M., Pleshko, N., and Mauck, R.L. Transient exposure to TGF-3 improves the functional chondrogenesis of MSC-laden hyaluronic acid hydrogels. J Mech Behav Biomed Mater 11, 92, 2012.

35. Farndale, R.W., Buttle, D.J., and Barrett, A.J. Improved quantitation and discrimination of sulphated glycosaminoglycans by use of dimethylmethylene blue. Biochim Biophys Acta 883, 173, 1986.

36. Stegemann, H., and Stalder, K. Determination of hydroxyproline. Clin Chim Acta 18, 267, 1967.

37. Kricheldorf, H.R. Handbook of Polymer Synthesis. New York: Marcel Dekker Inc., 1991.

38. Lozinsky, V.I., Simenel, I.A., Kurskaya, E.A., Kulakova, V.K., Galaev, I.Y., Mattiasson, B., Grinberg, V.Y., Grinberg, N.V., and Khokhlov, A.R. Synthesis of N-vinylcaprolactam polymers in water-containing media. Polymer 41, 6507, 2000.

39. Meeussen, F., Nies, E., Berghmans, H., Verbrugghe, S., Goethals, E., and Du Prez, F. Phase behaviour of poly $(\mathrm{N}-$ vinyl caprolactam) in water. Polymer 41, 8597, 2000.

40. Liu, J., Debuigne, A., Detrembleur, C., and Jérôme, C. Poly(N-vinylcaprolactam): a thermoresponsive macromolecule with promising future in biomedical field. Adv Healthc Mater 3, 1941, 2014.

41. Aguado, B.A., Mulyasasmita, W., Su, J., Lampe, K.J., and Heilshorn, S.C. Improving viability of stem cells during syringe needle flow through the design of hydrogel cell carriers. Tissue Eng Part A 18, 806, 2011.

42. Yu, L., and Ding, J. Injectable hydrogels as unique biomedical materials. Chem Soc Rev 37, 1473, 2008.

43. Sperling, L.H. Introduction to Physical Polymer Science. New Jersey: John Wiley \& Sons Inc., 2005.

44. Patenaude, M., Smeets, N.M.B., and Hoare, T. Designing injectable, covalently cross-linked hydrogels for biomedical applications. Macromol Rapid Commun 35, 598, 2014.

45. Patenaude, M., and Hoare, T. Injectable, degradable thermoresponsive poly(N-isopropylacrylamide) hydrogels. ACS Macro Lett 1, 409, 2012.

46. Mellati, A., Valizadeh Kiamahalleh, M., Dai, S., Bi, J., Jin, B., and Zhang, H. Influence of polymer molecular weight on the in vitro cytotoxicity of poly ( $\mathrm{N}$-isopropylacrylamide). Mater Sci Eng C 59, 509, 2016.

47. Williams, C.G., Malik, A.N., Kim, T.K., Manson, P.N., and Elisseeff, J.H. Variable cytocompatibility of six cell lines with photoinitiators used for polymerizing hydrogels and cell encapsulation. Biomaterials 26, 1211, 2005.

48. Lee, B., Jiao, A., Yu, S., You, J.B., Kim, D.-H., and Im, S.G. Initiated chemical vapor deposition of thermoresponsive poly(N-vinylcaprolactam) thin films for cell sheet engineering. Acta Biomater 9, 7691, 2013.

49. Kumar, D., Lyness, A., Gerges, I., Lenardi, C., Forsyth, N.R., and Liu, Y. Stem cell delivery with polymer hydrogel for treatment of intervertebral disc degeneration: from 3D culture to design of the delivery device for minimally invasive therapy. Cell Transplant 25, 2213, 2016.

50. Chen, J.-P., and Cheng, T.-H. Thermo-responsive chitosangraft-poly(N-isopropylacrylamide) injectable hydrogel for cultivation of chondrocytes and meniscus cells. Macromol Biosci 6, 1026, 2006.
51. Peyton, S.R., Ghajar, C.M., Khatiwala, C.B., and Putnam, A.J. The emergence of ECM mechanics and cytoskeletal tension as important regulators of cell function. Cell Biochem Biophys 47, 300, 2007.

52. Yourek, G., Hussain, M.A., and Mao, J.J. Cytoskeletal changes of mesenchymal stem cells during differentiation. ASAIO J 53, 219, 2007.

53. Shakya, A.K., Kumar, A., and Nandakumar, K.S. Adjuvant properties of a biocompatible thermo-responsive polymer of $N$-isopropylacrylamide in autoimmunity and arthritis. J R Soc Interface 8, 1748, 2011.

54. Elisseeff, J. Injectable cartilage tissue engineering. Expert Opin Biol Ther 4, 1849, 2004.

55. Schuh, E., Hofmann, S., Stok, K., Notbohm, H., Müller, R., and Rotter, N. Chondrocyte redifferentiation in 3D: the effect of adhesion site density and substrate elasticity. J Biomed Mater Res A 100A, 38, 2012.

56. Roberts, S., Menage, J., Sandell, L.J., Evans, E.H., and Richardson, J.B. Immunohistochemical study of collagen types I and II and procollagen IIA in human cartilage repair tissue following autologous chondrocyte implantation. Knee 16, 398, 2009.

57. Wang, L.-S., Du, C., Toh, W.S., Wan, A.C.A., Gao, S.J., and Kurisawa, M. Modulation of chondrocyte functions and stiffness-dependent cartilage repair using an injectable enzymatically crosslinked hydrogel with tunable mechanical properties. Biomaterials 35, 2207, 2014.

58. Yuan, L., Li, B., Yang, J., Ni, Y., Teng, Y., Guo, L., Fan, H., Fan, Y., and Zhang, X. Effects of composition and mechanical property of injectable collagen I/II composite hydrogels on chondrocyte cehaviors. Tissue Eng Part A 22, 899, 2016.

59. Park, K.-H., Lee, D.H., and Na, K. Transplantation of poly(N-isopropylacrylamide-co-vinylimidazole) hydrogel constructs composed of rabbit chondrocytes and growth factor-loaded nanoparticles for neocartilage formation. Biotechnol Lett 31, 337, 2009.

60. Peroglio, M., Grad, S., Mortisen, D., Sprecher, C.M., IllienJünger, S., Alini, M., and Eglin, D. Injectable thermoreversible hyaluronan-based hydrogels for nucleus pulposus cell encapsulation. Eur Spine J 21, 839, 2012.

61. Peroglio, M., Eglin, D., Benneker, L.M., Alini, M., and Grad, S. Thermoreversible hyaluronan-based hydrogel supports in vitro and ex vivo disc-like differentiation of human mesenchymal stem cells. Spine J 13, 1627, 2013.

62. Taguchi, T., Xu, L., Kobayashi, H., Taniguchi, A., Kataoka, K., and Tanaka, J. Encapsulation of chondrocytes in injectable alkali-treated collagen gels prepared using poly(ethylene glycol)-based 4-armed star polymer. Biomaterials 26, 1247, 2005.

63. Park, H., Choi, B., Hu, J., and Lee, M. Injectable chitosan hyaluronic acid hydrogels for cartilage tissue engineering. Acta Biomater 9, 4779, 2013.

Address correspondence to: Jason A. Burdick, PhD Department of Bioengineering University of Pennsylvania Philadelphia, PA 19104

E-mail: burdick2@seas.upenn.edu

Received: October 23, 2016

Accepted: February 16, 2017

Online Publication Date: April 6, 2017 